\title{
The role of ZFP580, a novel zinc finger protein, in TGF-mediated cytoprotection against chemical hypoxia-induced apoptosis in $\mathrm{H} 9 \mathrm{c} 2$ cardiac myocytes
}

\author{
SHI-YUN MAO ${ }^{1 *}$, XIANG-YAN MENG ${ }^{2 *}$, ZHONG-WEI XU ${ }^{3}$, WEN-CHENG ZHANG ${ }^{2}$, \\ XIAO-HAN JIN ${ }^{4}, \mathrm{XI} \mathrm{CHEN}^{5}, \mathrm{XIN}_{\mathrm{ZHOU}}^{4}$, YU-MING $\mathrm{LI}^{4}$ and RUI-CHENG XU ${ }^{5}$ \\ ${ }^{1}$ Sichuan Provincial Corps Hospital, Chinese People's Armed Police Forces, Leshan, Sichuan 614000; \\ ${ }^{2}$ Department of Physiology and Pathophysiology; ${ }^{3}$ Central Laboratory, Logistics University of \\ Chinese People's Armed Police Force, Tianjin 300309; ${ }^{4}$ Tianjin Key Laboratory of Cardiovascular Remodeling \\ and Target Organ Injury, Pingjin Hospital Heart Center, Tianjin 300162; ${ }^{5}$ Tianjin Key Laboratory \\ for Prevention and Control of Occupational and Environmental Hazard, Logistics University \\ of Chinese People's Armed Police Force, Tianjin 300309, P.R. China
}

Received December 19, 2015; Accepted December 22, 2016

DOI: $10.3892 / \mathrm{mmr} .2017 .6236$

\begin{abstract}
Zing finger protein 580(ZFP580) is a novelCys2-His2 zinc-finger transcription factor that has an anti-apoptotic role in myocardial cells. It is involved in the endothelial transforming growth factor- $\beta 1$ (TGF- $\beta 1$ ) signal transduction pathway as a mothers against decapentaplegic homolog (Smad)2 binding partner. The aim of the present study was to determine the involvement of ZFP580 in TGF- $\beta 1$-mediated cytoprotection against chemical hypoxia-induced apoptosis, using $\mathrm{H} 9 \mathrm{c} 2$ cardiac myocytes. Hypoxia was chemically induced in H9c2 myocardial cells by exposure to cobalt chloride $\left(\mathrm{CoCl}_{2}\right)$. In response to hypoxia, cell viability was decreased, whereas the expression levels of hypoxia inducible factor- $1 \alpha$ and ZFP580 were increased. Pretreatment with TGF- $\beta 1$ attenuated $\mathrm{CoCl}_{2}$-induced cell apoptosis and upregulated ZFP580 protein
\end{abstract}

Correspondence to: Professor Yu-Ming Li, Tianjin Key Laboratory of Cardiovascular Remodeling and Target Organ Injury, Pingjin Hospital Heart Center, 220 Chenglin Road, Tianjin 300162, P.R. China

E-mail: cardiolab@gmail.com

Mr. Rui-Cheng Xu, Tianjin Key Laboratory for Prevention and Control of Occupational and Environmental Hazard, Logistics University of Chinese People's Armed Police Force, 1 Huizhihuan Road, Dongli, Tianjin 300309, P.R. China

E-mail: xu_ruicheng1968@126.com

*Contributed equally

Abbreviations: TGF- $\beta 1$, transforming growth factor- $\beta 1 ; \mathrm{CoCl}_{2}$, cobalt chloride; T $\beta$ R-I, TGF- $\beta$ type I receptor

Key words: transforming growth factor- $\beta$, cardiomyocyte, hypoxia, zinc finger proteins, apoptosis expression; however, these effects could be suppressed by SB431542, an inhibitor of TGF- $\beta$ type I receptor and Smad2/3 phosphorylation. Furthermore, suppression of ZFP580 expression by RNA interference reduced the anti-apoptotic effects of TGF- $\beta 1$ and thus increased $\mathrm{CoCl}_{2}$-induced apoptosis. B-cell lymphoma (Bcl)-2-associated $\mathrm{X}$ protein/Bcl-2 ratio, reactive oxygen species generation and caspase-3 activation were also increased following ZFP580 inactivation. In conclusion, these results indicate that ZFP580 is a component of the TGF- $\beta 1 /$ Smad signaling pathway, and is involved in the protective effects of TGF- $\beta 1$ against chemical hypoxia-induced cell apoptosis, through inhibition of the mitochondrial apoptotic pathway.

\section{Introduction}

Zing finger protein 580 (ZNF580) is a novel gene that is associated with low-density lipoprotein stimulation in vascular endothelial cells. ZNF580 gene cloning (1) and subsequent bioinformatics analysis revealed that ZNF580 is a Cys2-His2 (C2H2)-type transcription factor (2). C2H2-zinc finger genes constitute the largest class of transcription factors within the human genome; they are typically involved in critical cell functions, such as survival and growth (3). Our previous study indicated that ZNF580 is ubiquitously expressed in human tissues, and serves important roles in maintaining normal cell functions, including migration and proliferation (4,5). ZFP580 is the murine homologue of ZNF580, research regarding cloned ZFP580 (6) revealed that intermittent hypoxia could induce expression, which displayed an anti-apoptotic role during early phase ischemia-reperfusion injury (7). However, the mechanism and signaling pathways underlying the anti-apoptotic effects of ZFP580 have not yet been fully elucidated.

Members of the transforming growth factor- $\beta$ (TGF- $\beta$ ) family regulate numerous cellular functions, including cell growth, differentiation, adhesion, migration and apoptosis. TGF- $\beta 1$ is a multifunctional cytokine that regulates apoptosis 
in a cell type-specific and context-dependent manner, with proapoptotic or anti-apoptotic actions depending on the target cell type and the pathophysiologic milieu (8-10). Despite its proapoptotic role in several cell types, TGF- $\beta 1$ demonstrated cardioprotective effects during reperfusion injury or cardiac inflammatory disease in myocytes (11-13), and exerted an anti-apoptotic role in hypoxia-reoxygenation-induced myocardial cell injury $(12,14,15)$.

Mothers against decapentaplegic homolog (Smad) proteins are the primary intracellular mediators of the TGF- $\beta 1$ signaling pathway. Smad2 and Smad3 are particularly important in the transcriptional response to TGF- $\beta 1$, in various physiological scenarios. Our previous study determined that ZNF580 is involved in the TGF- $\beta 1$ signaling pathway as a binding partner of Smad2 (16,17). However, the actual relationship between ZFP580 and Smad proteins in cobalt chloride $\left(\mathrm{CoCl}_{2}\right)$-induced apoptosis has not been fully elucidated. Therefore, the present study aimed to investigate the involvement of ZFP580 in TGF- $\beta 1$-mediated cytoprotection during $\mathrm{CoCl}_{2}$-induced apoptosis, and its association with Smad2 in embryonic rat heart H9c2 cells.

\section{Materials and methods}

Materials. SB431542, $\mathrm{CoCl}_{2}, 3$-(4,5-dimethylthiazol-2-yl)-2, 5-diphenyltetrazolium bromide (MTT) and 2,7-dichlorofluorescin diacetate (DCFH-DA) were provided by Sigma-Aldrich (Merck Millipore, Darmstadt, Germany). Recombinant human TGF- $\beta 1$ was purchased from PeproTech, Inc. (Rocky Hill, NJ, USA). Anti-ZNF580 (catalog no. ab59015), anti-hypoxia inducible factor (HIF)-1 $\alpha$ (ab463), anti-phosphorylated Smad (p-Smad)-2 (phospho S467; ab53100), anti-p-Smad3 (phospho S425; ab51177), and anti-active caspase-3 (ab2302) primary antibodies were purchased from Abcam (Cambridge, UK). Anti-Smad2 (sc-393312), anti-Smad3 (sc-101154), anti-B-cell lymphoma 2 (Bcl-2; sc-783), anti-Bcl-2-associated $\mathrm{X}$ protein (Bax; sc-526), and anti- $\beta$-actin (sc-47778) antibodies were purchased from Santa Cruz Biotechnology Inc. (Dallas, TX, USA). The Annexin V-fluorescein isothiocyanate (FITC)/propidium iodide (PI) Apoptosis Detection kit was supplied by Promega Corp. (Madison, WI, USA), and the high-glucose Dulbecco's modified Eagle's medium (DMEM) and fetal bovine serum (FBS) were purchased from Gibco (Thermo Fisher Scientific Inc., Waltham, MA, USA). The carbon dioxide independent DMEM was purchased from the Medical Gas Company (Tianjin, China).

Cell culture and hypoxia induction. The embryonic rat heart-derived cell line (H9c2) was obtained from the Cell Bank of Type Culture Collection of Chinese Academy of Sciences (Shanghai, China). H9c2 cells were cultured in DMEM supplemented with $10 \%$ FBS and $1 \%$ penicillin-streptomycin in a humidified atmosphere containing $5 \% \mathrm{CO}_{2}$ at $37^{\circ} \mathrm{C}$. The hypoxia model was established using the hypoxia-inducing agent $\mathrm{CoCl}_{2}$, according to a previous study (18).

Cell viability assessment under various hypoxic conditions. Cells at a density of $1 \times 10^{4} / 200 \mu 1$ were plated in DMEM supplemented with $10 \%$ FBS, in 96-well microtiter plates (Corning Life Sciences, USA) and incubated for $24 \mathrm{~h}$ at $37^{\circ} \mathrm{C}$. Cells were subsequently incubated in serum-free $\mathrm{CO}_{2}$-independent DMEM supplemented with various concentrations of $\mathrm{CoCl}_{2}(200,400,600,800$ and 1,000 $\mu \mathrm{M})$ for $24 \mathrm{~h}$, or with $600 \mu \mathrm{M} \mathrm{CoCl}_{2}$ for various time intervals $(0,4,8,12$, 16,20 and $24 \mathrm{~h}$ ). Normoxic control cells were incubated under the same conditions but in a normal atmosphere Normoxic cells received normal serum and no $\mathrm{CoCl}_{2}$ treatment, and the hypoxic cells were then incubated in a hypoxic chamber. MTT was added at a final concentration of $0.5 \mathrm{mg} / \mathrm{ml}$. After a 4 -h incubation at $37^{\circ} \mathrm{C}$, the reaction was halted by adding $200 \mu 1$ dimethyl sulfoxide, and the relative optical density was measured at $490 \mathrm{~nm}$ by a microplate spectrophotometer (BioTek Instruments, Inc., Winooski, VT, USA). Cell viability was calculated according to the following equation: Cell viability $(\%)=\left(\mathrm{OD}_{\text {treatment }}-\mathrm{OD}_{\text {blank }}\right) /\left(\mathrm{OD}_{\text {control }}-\mathrm{OD}_{\text {blank }}\right) \times 100$. Experiments were performed in triplicate. To analyze TGF- $\beta 1$ function under hypoxic conditions, cell viability was measured following pretreatment with $2 \mathrm{ng} / \mathrm{ml} \mathrm{TGF}-\beta 1$ for $30 \mathrm{~min}$, prior to exposure to $600 \mu \mathrm{M} \mathrm{CoCl}_{2}$ for 8,16 or $24 \mathrm{~h}$. To analyze the role of $\mathrm{Smad} 2 / 3$ in the TGF- $\beta 1$-mediated cytoprotection against $\mathrm{CoCl}_{2}$-induced hypoxia, $\mathrm{H} 9 \mathrm{c} 2$ cells were pretreated with SB431542 (20 $\mu \mathrm{M}$, diluent with DMSO, at $\left.37^{\circ} \mathrm{C}\right)$, a selective inhibitor of T $\beta R 1-\operatorname{Smad} 2 / 3$, prior to stimulation with TGF- $\beta 1$, and were subsequently exposed to $600 \mu \mathrm{M} \mathrm{CoCl}_{2}$ for $24 \mathrm{~h}$.

RNA extraction, cDNA synthesis, and reverse transcription-quantitative polymerase chain reaction ( $R T-q P C R)$. Total RNA from $\mathrm{H} 9 \mathrm{c} 2$ cells treated with $600 \mu \mathrm{M} \mathrm{CoCl}_{2}$ at various time intervals $(0,4,8,12,16,20$ or $24 \mathrm{~h})$ was isolated using TRIzol reagent (Invitrogen; Thermo Fisher Scientific, Inc.) according to the manufacturer's protocol. First-strand cDNA samples were synthesized using a TransScript First-Strand cDNA Synthesis Supermix kit according to the manufacturer's protocol (Beijing Transgen Biotech, Co., Ltd., Beijing, China). GAPDH RNA levels were quantified in all of the samples as an internal control, and mRNA levels were calculated relative to GAPDH mRNA. qPCR was performed in a $25 \mu \mathrm{l}$ volume with SYBR ${ }^{\circledR}$ Green PCR Master Mix (Applied Biosystems; Thermo Fisher Scientific, Inc.). Each gene analysis was repeated at least 3 times, and all RT-qPCR experiments were performed in triplicate using the ABI 7500 Real-Time PCR platform (Applied Biosystems; Thermo Fisher Scientific, Inc.) The specific primers used were as follows: Forward, 5'-ACATCA TTTCGTCTTTTCTTCTG-3' and reverse, 5'-GGTGCTTTT GTCATTTCTTCCAC-3' for ZFP580. The PCR conditions for ZFP580 were $15 \mathrm{sec}$ at $95^{\circ} \mathrm{C}, 34 \mathrm{sec}$ at $63^{\circ} \mathrm{C}$ and $45 \mathrm{sec}$ at $72^{\circ} \mathrm{C}$ for 40 cycles. Expression of glyceraldehyde-3-phosphate dehydrogenase (GAPDH), a housekeeping gene, served as an internal control. The fold-change in expression of the gene of interest between the two samples was calculated using the $\Delta \Delta \mathrm{Cq}$ method (19).

Western blot analysis. Cells were lysed with radioimmunoprecipitation assay buffer [50 mM Tris- $\mathrm{HCl}(\mathrm{pH} 7.4), 150 \mathrm{mM}$ $\mathrm{NaCl}, 0.1 \%$ SDS, $1 \%$ NP-40, and protease inhibitor cocktail] for $30 \mathrm{~min}$ and centrifuged at $12,000 \mathrm{x} g$ for $10 \mathrm{~min}$ prior to supernatant collection. The protein concentration was quantified using the bicinchoninic acid assay. Equal amounts $(60 \mu \mathrm{g})$ of protein were loaded into each lane and separated by 
10\% SDS-PAGE, then transferred to polyvinylidene fluoride (PVDF) membranes (Roche Diagnostics GmbH, Mannheim, Germany). After blocking in 5\% fat-free milk in Tris-buffered saline-Tween-20 (TBST) for $1 \mathrm{~h}$ at room temperature, the PVDF membranes were incubated with primary antibodies $(1: 2,000)$ overnight at $4^{\circ} \mathrm{C}$. The membranes were washed with TBST and then incubated with horseradish peroxidase-conjugated anti-rabbit (L3012, Signalway Antibody, Nanjing, China) or anti-mouse (L3032, Signalway Antibody) secondary antibodies in TBST $(1: 5,000)$ for $1 \mathrm{~h}$ at room temperature, and then visualized by a super enhanced chemiluminescence detection reagent (Beyotime Institute of Biotechnology, Haimen, China). The signals were detected using Image Station 4000R (Kodak, Rochester, NY, USA). Quantification of results was performed using Image J version 1.44 (National Institutes of Health, Bethesda, MD, USA). Each experiment was repeated at least three times.

Flow cytometric analysis. The aforementioned treated H9c2 cells were collected as previously described (20). Briefly, cell supernatants were incubated with $5 \mu \mathrm{l}$ Annexin V-FITC and $10 \mu \mathrm{l}$ propidium iodide (PI) for $15 \mathrm{~min}$ in the dark. Following incubation, $400 \mu \mathrm{l}$ binding buffer was added to each sample and the samples were then filtered through a $50 \mu \mathrm{m}$ nylon mesh. Fluorescence was analyzed by flow cytometry Epics Elite flow cytometer (BD Immunocytometry Systems, San Jose, CA, USA). Cells display phosphatidylserine on their outer cell membranes, which is readily detected by Annexin $\mathrm{V}$ during the early stages of apoptosis. The plasma membrane becomes increasingly permeable during the later stages of apoptosis, and PI may move across the cell membrane to bind to cellular DNA. The data were analyzed using FlowJo 7.6 software (FlowJo, LLC, Ashland, OR, USA). Cells in the fourth quadrant indicated the presence of apoptotic cells.

Lentiviral infection. Lentiviral vectors expressing small interfering RNAs (siRNAs) directed against ZFP580 (Lenti-RNAi) or a negative control (Lenti-NC) were constructed by Shanghai GenePharma Co., Ltd. (Shanghai, China). H9c2 cells were cultured to $30-40 \%$ confluence and were then infected with either the Lenti-RNAi or Lenti-NC for $72 \mathrm{~h}$ at $37^{\circ} \mathrm{C}$ [multiple of infection $(\mathrm{MOI})=50]$. The infected cells were treated with or without $2 \mathrm{ng} / \mathrm{ml} \mathrm{TGF}-\beta 1$ for $30 \mathrm{~min}$ prior to exposure to $600 \mu \mathrm{M} \mathrm{CoCl}_{2}$ for $24 \mathrm{~h}$.

Fluorescence assay of intracellular reactive oxygen species (ROS). Intracellular ROS generation was determined using the ROS-dependent oxidative conversion of cell-permeable DCFH-DA to the fluorescent dichlorofluorescein. H9c2 cells were treated as aforementioned, washed 3 times with PBS, and incubated with a $10 \mu \mathrm{M}$ DCFH-DA solution in serum-free medium at $37^{\circ} \mathrm{C}$, for $30 \mathrm{~min}$, in the dark. Cells were washed 3 times with PBS, and ROS concentrations were quantified using a Leica TSP SP8 confocal microscope at a wavelength of $485 \mathrm{~nm}$ (Leica Microsystems GmbH, Wetzlar, Germany) and a SpectraMax M2 microplate reader at a wavelength of $530 \mathrm{~nm}$ (Molecular Devices, LLC, Sunnyvale, CA, USA).

Statistical analysis. All data are presented as the mean \pm standard error. Data were analyzed using SPSS software version
18.0 (SPSS, Inc., Chicago, IL, USA). Statistically significant differences were determined using one-way analysis of variance, followed by the least significant difference test. $\mathrm{P}<0.05$ was considered to indicate a statistically significant difference.

\section{Results}

$\mathrm{CoCl}_{2}$ reduces cell viability and increases expression of ZFP580 and HIF-1 $\alpha$ in H9c2 myocardial cells. MTT assay revealed that $\mathrm{CoCl}_{2}$ treatment decreased cell viability in a concentration- and time- dependent manner (Fig. 1A and B). Cell viability decreased following a $24 \mathrm{~h}$ incubation with increasing concentrations of $\mathrm{CoCl}_{2}(400,600,800$ or $1,000 \mu \mathrm{M}) ; 600 \mu \mathrm{M} \mathrm{CoCl}_{2}$ was sufficient to decrease viability by $\sim 50 \%$. Based on these results a concentration of $600 \mu \mathrm{M}$ $\mathrm{CoCl}_{2}$ was selected for a time-course experiment investigating the effects of $\mathrm{CoCl}_{2}$ on cell viability at different time intervals $(0,4,8,12,16,20$ or $24 \mathrm{~h})$. The results indicated that cell viability was significantly decreased at 8, 12, 16, 20 and $24 \mathrm{~h}$ after $\mathrm{CoCl}_{2}$ treatment compared with the control group $(\mathrm{P}<0.05$; Fig. 1B). Western blot analysis indicated that the protein expression levels of HIF-1 $\alpha$, a marker of hypoxia, rose during hypoxia and peaked at $12 \mathrm{~h}$; however, HIF-1 $\alpha$ mRNA levels, as determined by RT-qPCR, did not significantly increase during the same time period (Fig. 1C and $\mathrm{D})$; this result is consistent with previously reported research $(21,22)$. $\mathrm{CoCl}_{2}$ treatment increased ZFP580 expression at mRNA and protein levels; ZFP580 mRNA expression peaked at $12 \mathrm{~h}$, and protein expression peaked at $16 \mathrm{~h}$ (Fig. 1C and E). Notably, cell viability steadily decreased in hypoxia-induced cells, whereas the expression of ZFP580 increased and then decreased after $16 \mathrm{~h}$. This may be due to the role of ZFP580 as an anti-injury marker (7), where it is first activated then degraded with increasing hypoxia. These findings indicated that a $\mathrm{CoCl}_{2}$-induced hypoxia model of $\mathrm{H} 9 \mathrm{c} 2$ cells had been successfully established; in addition, it was observed that $\mathrm{CoCl}_{2}$-induced hypoxia increases ZFP580 expression.

TGF- $\beta 1$ attenuates $\mathrm{CoCl}_{2}$-induced cytotoxicity and upregulates ZFP580 protein expression. To analyze TGF- $\beta 1$ function under hypoxic conditions, $\mathrm{H} 9 \mathrm{c} 2$ cells were pretreated with $2 \mathrm{ng} / \mathrm{ml} \mathrm{TGF}-\beta$ for $30 \mathrm{~min}$ prior to exposure to $600 \mu \mathrm{M} \mathrm{CoCl}_{2}$ for 8,16 or $24 \mathrm{~h}$. MTT assay revealed that pretreatment with TGF- $\beta 1$ reduced $\mathrm{CoCl}_{2}$-induced cytotoxicity and increased cell viability by $\sim 10 \%$ at 16 and $24 \mathrm{~h}$, compared with that of the untreated hypoxic group (Fig. 2A; P<0.05). Western blot analysis indicated that ZFP580 protein expression was upregulated by pretreatment with TGF- $\beta 1$ and subsequent exposure to $\mathrm{CoCl}_{2}$ (Fig. 2B and C). ZFP580 expression was upregulated at 8 and $24 \mathrm{~h}$ following TGF- $\beta 1$ and $\mathrm{CoCl}_{2}$ treatment $(\mathrm{P}<0.05)$; however, there was no difference in ZFP580 expression at the TGF- $\beta 1$-treated $16 \mathrm{~h}$ time-point, regardless of $\mathrm{CoCl}_{2}$ treatment. It is possible that ZFP580 protein levels had plateaued at this time point. At $24 \mathrm{~h}$ there were clear differences in both cell viability and ZFP580 expression in the TGF- $\beta 1$ pretreatment group, with or without $\mathrm{CoCl}_{2}$ treatment; therefore, at $24 \mathrm{~h}$, $600 \mu \mathrm{M} \mathrm{CoCl}_{2}$ treatment was selected for subsequent experimental conditions. From these findings it was hypothesized 


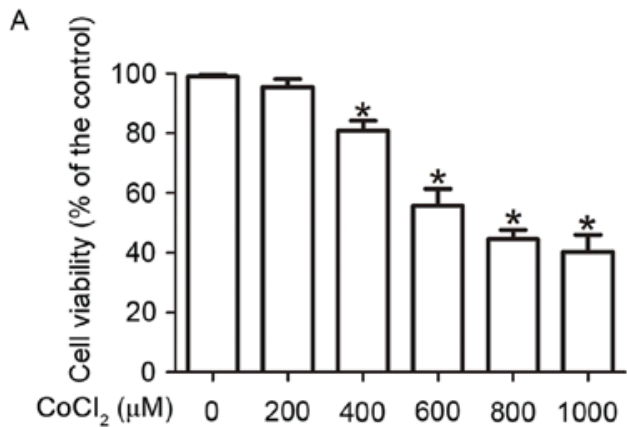

C

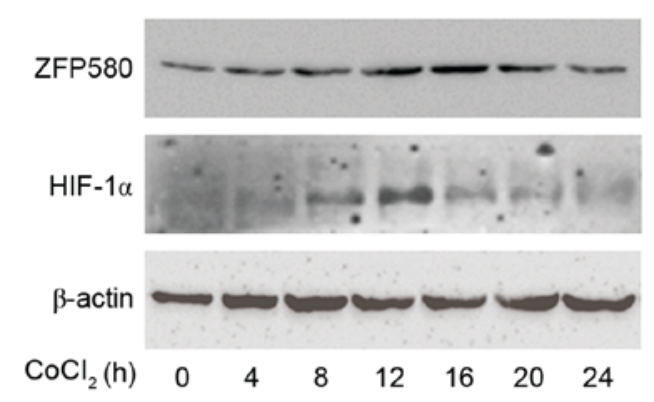

E

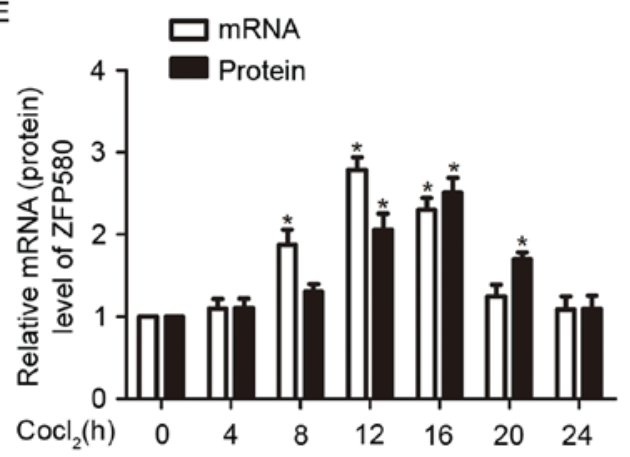

A

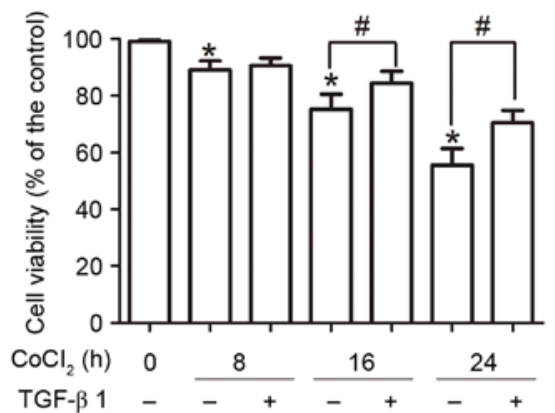

C

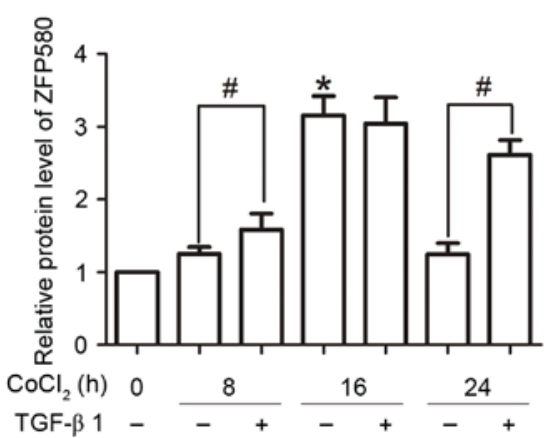

B
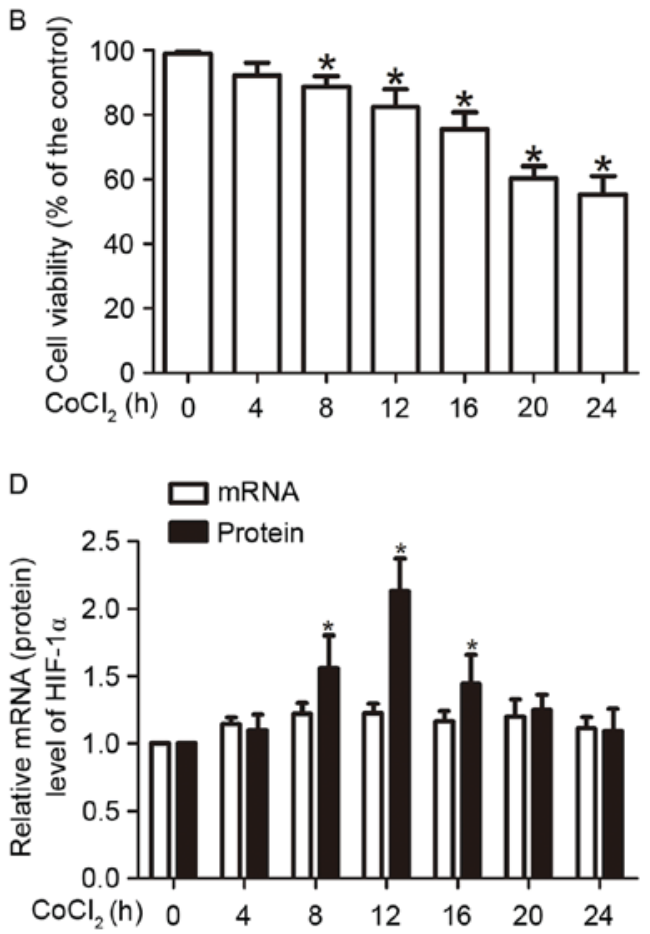

Figure 1. Effects of $\mathrm{CoCl}_{2}$ on cell viability and the expression of ZFP580 or HIF-1 $\alpha$ n H9c2 myocardial cells. (A) H9c2 cells were treated with $0,200,400$, 600,800 or $1,000 \mu \mathrm{M} \mathrm{CoCl}_{2}$ for $24 \mathrm{~h}$. The concentration-dependent effects of $\mathrm{CoCl}_{2}$ on cell survival were assessed by MTT assay. (B) H9c2 cells were treated with $600 \mu \mathrm{M} \mathrm{CoCl}_{2}$ for $0,4,8,12,16,20$ or $24 \mathrm{~h}$. The time-dependent effects of $\mathrm{CoCl}_{2}$ on cell survival were assessed by MTT assay. H9c2 cells were treated with $600 \mu \mathrm{M} \mathrm{CoCl}_{2}$ for 0 to $24 \mathrm{~h}$, and expression of (C) HIF-10 and ZFP580 protein, or (D) HIF-1 $\alpha$ and (E) ZFP580 mRNA were determined by western blot analysis or reverse transcription-quantitative polymerase chain reaction, respectively. Three experiments were performed for each group, and each experiment was replicated twice. The results are presented as the mean \pm standard error. " $\mathrm{P}<0.05$ vs. control. $\mathrm{CoCl}_{2}$, cobalt chloride; HIF-1 $\alpha$, hypoxia-inducible factor- $1 \alpha$; ZFP580, zinc finger protein 580; MTT, 3-(4,5-dimethylthiazol-2-yl)-2, 5-diphenyltetrazolium bromide.

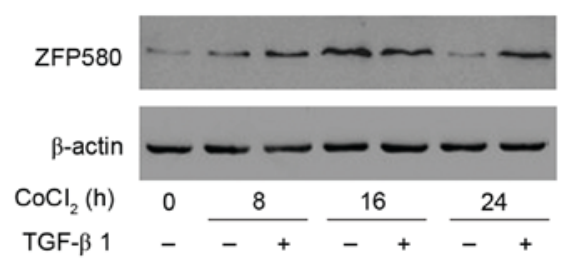

Figure 2. TGF- $\beta 1$ attenuated $\mathrm{CoCl}_{2}$-induced cytotoxicity and upregulated ZFP580 protein expression. (A) MTT results indicated that pretreatment with TGF- $\beta 1$ increased cell viability after $\mathrm{CoCl}_{2}$ treatment. (B and C) $\mathrm{H} 9 \mathrm{c} 2$ cells were pretreated with TGF- $\beta 1$ and then exposed to $600 \mu \mathrm{M} \mathrm{CoCl}_{2}$ for 8,16 or $24 \mathrm{~h}$, the ZFP580 protein expression was determined by western blot analysis. Three experiments were performed for each group, and each experiment was repeated twice. The results are presented as the mean \pm standard error. ${ }^{*} \mathrm{P}<0.05$ vs. control, ${ }^{*} \mathrm{P}<0.05$ vs. the $\mathrm{CoCl}_{2}$ treatment control group. TGF- $\beta 1$, transforming growth factor- $\beta 1 ; \mathrm{CoCl}_{2}$, cobalt chloride; ZFP580, zinc finger protein 580; MTT, 3-(4,5-dimethylthiazol-2-yl)-2, 5-diphenyltetrazolium bromide. 
A

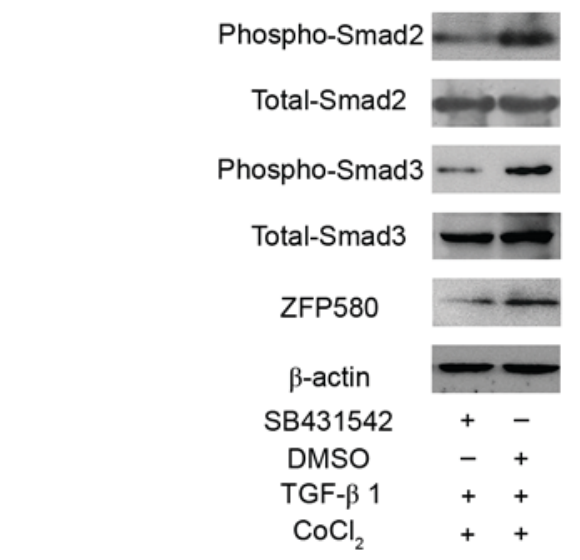

C
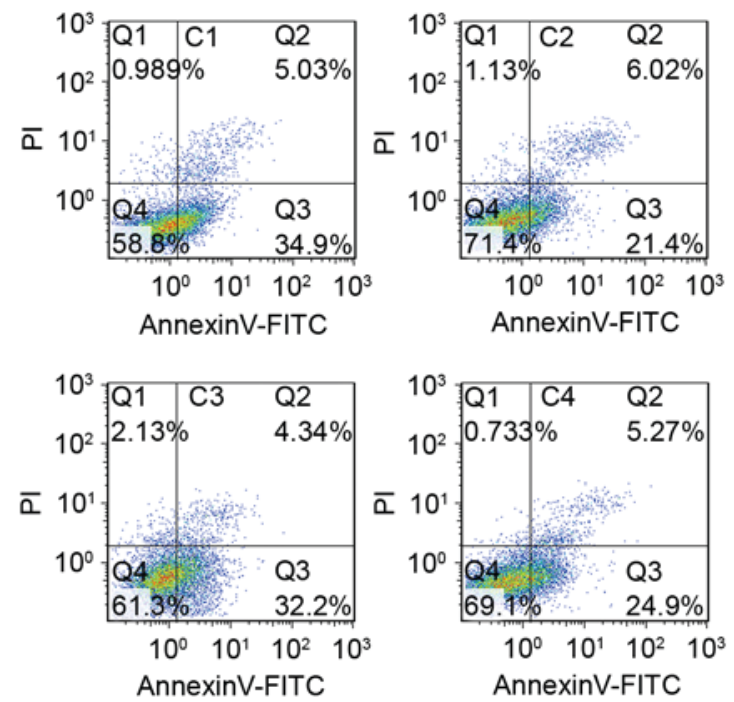

B

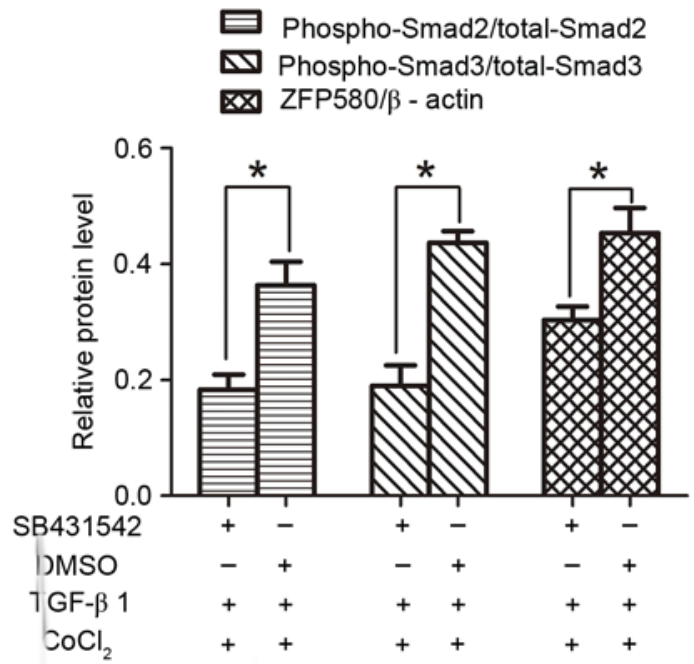

D

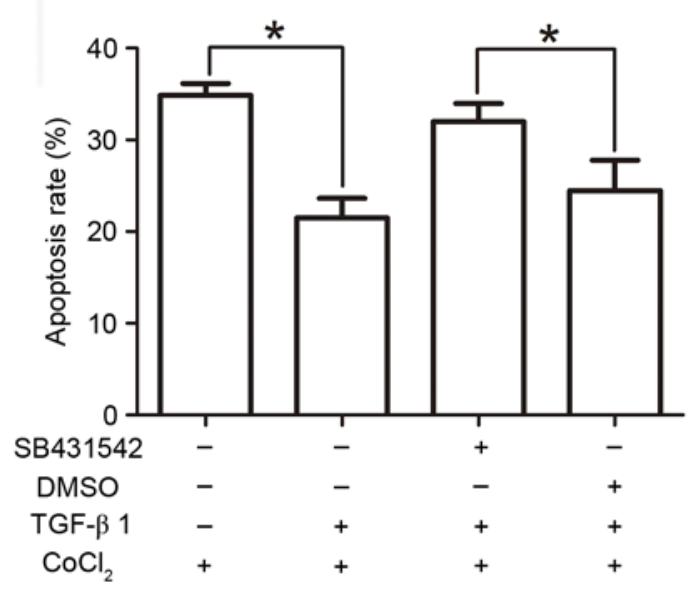

Figure 3. Inhibition of T $\beta$ R1-Smad2/3 activation attenuated ZFP580 protein expression and the protective effects of TGF- $\beta 1$ against CoCl ${ }_{2}$-induced apoptosis $\mathrm{H} 9 \mathrm{c} 2$ cells were pretreated with SB431542, a selective inhibitor of T $\beta \mathrm{R} 1-\mathrm{Smad} 2 / 3$, prior to stimulation with TGF- $\beta 1$, and were subsequently exposed to $600 \mu \mathrm{M} \mathrm{CoCl}_{2}$ for $24 \mathrm{~h}$. (A) Protein expression and (B) histogram analysis detected Smad2/3 activation and ZFP580 expression in H9c2 cells with or without SB431542 pretreatment. (C) Cells (1x104) were subjected to AnnexinV-FITC/PI staining and analyzed by flow cytometry. C1, Control group; C2, TGF- $\beta 1$ induction group; C3, SB431542 pretreatment and TGF- $\beta 1$ induction group; $\mathrm{C} 4$, DMSO pretreatment and TGF- $\beta 1$ induction group, all exposed to CoCl ${ }_{2}$. (D) Representative histograms for the cell apoptosis rates in $\mathrm{H} 9 \mathrm{c} 2$ cells. Three experiments were performed for each group, and each experiment was repeated twice. The results are presented as the mean \pm standard error. " $\mathrm{P}<0.05$. TGF- $\beta 1$, transforming growth factor- $\beta 1$; T $\beta \mathrm{R} 1$, TGF- $\beta$ type I receptor; Smad, mothers against decapentaplegic homolog; ZFP580, zinc finger protein 580; $\mathrm{CoCl}_{2}$, cobalt chloride; DMSO, dimethyl sulfoxide; FITC, fluorescein isothiocyanate; PI, propidium iodide.

that ZFP580 is involved in the TGF- $\beta 1$-mediated defensive mechanisms against $\mathrm{CoCl}_{2}$-induced injury.

Inhibition of Smad2/3 activation attenuates ZFP580 protein expression and TGF- $\beta 1$-mediated cytoprotection against $\mathrm{CoCl}_{2}$-induced apoptosis. Smad2 and Smad3 are important cofactors in TGF- $\beta 1$ signal transduction. To analyze the role of $\mathrm{Smad} 2 / 3$ in the TGF- $\beta 1$-mediated cytoprotection against $\mathrm{CoCl}_{2}$-induced hypoxia, $\mathrm{H} 9 \mathrm{c} 2$ cells were first pretreated with SB431542, a well-known selective inhibitor of TGF- $\beta$ type I receptor (T $\beta$ R-I) and Smad $2 / 3$ activation. Following SB431542 treatment, cells were stimulated with TGF- $\beta 1$, and subsequently exposed to $\mathrm{CoCl}_{2}$. Western blot analysis indicated that SB431542 partially blocked the TGF- $\beta 1$-induced upregulation of ZFP580 expression (Fig. 3A and B). Flow cytometric analysis demonstrated that pretreatment with TGF- $\beta 1$ significantly decreased the proportion of apoptotic cells after $\mathrm{CoCl}_{2}$ treatment $(20.64 \pm 2.14$ vs. $35.68 \pm 1.30 \%$; $\mathrm{P}<0.05)$; whereas inhibition of $\mathrm{Smad} 2 / 3$ activation appeared to reduce these protective effects by increasing the amount of apoptosis by $~ 8 \%$ (from $23.46 \pm 3.33$ to $31.97 \pm 2.00 \%$; $\mathrm{P}<0.05$; Fig. $3 \mathrm{C}$ and D). These findings demonstrated that ZFP580, as a downstream target of the TGF- $\beta 1 / \mathrm{Smad} 2 / 3$ signaling pathway, may be associated with the protective role mediated by TGF- $\beta 1$ against $\mathrm{CoCl}_{2}$-induced cell apoptosis. 
A
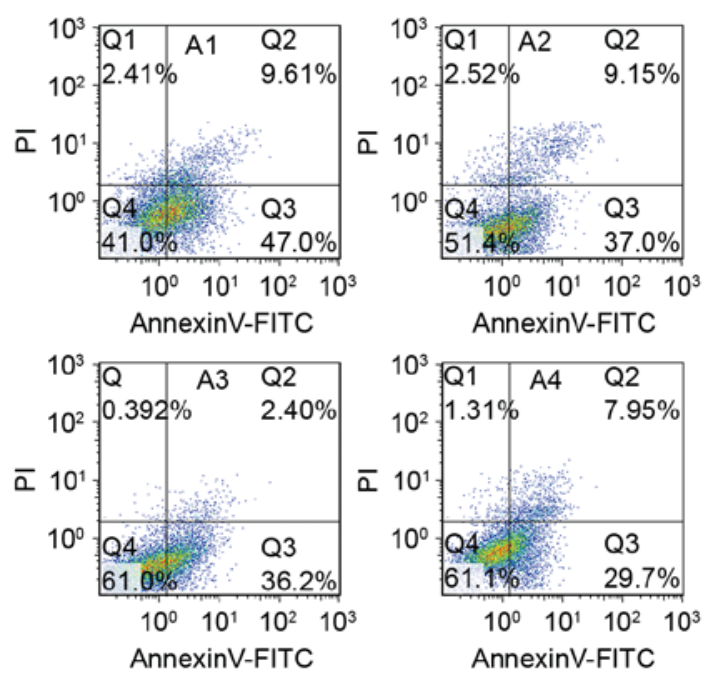

C
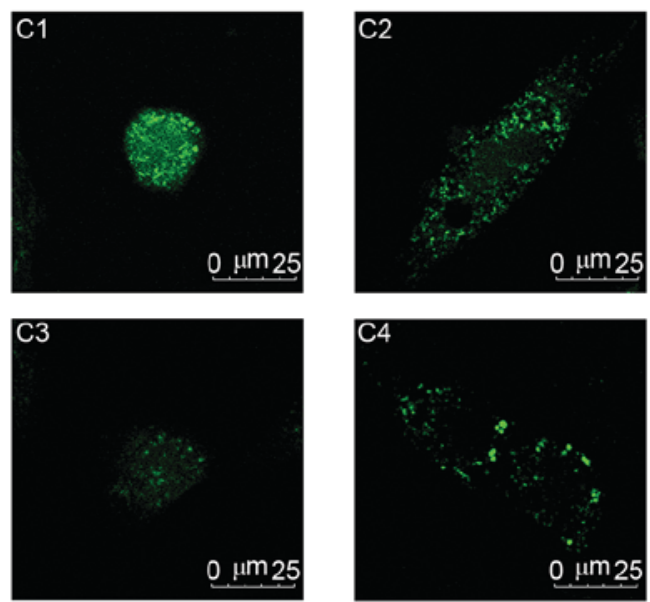

B

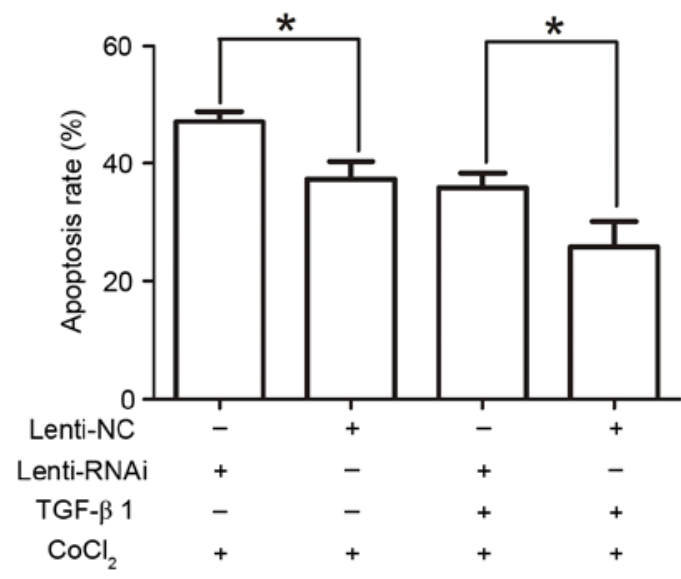

D

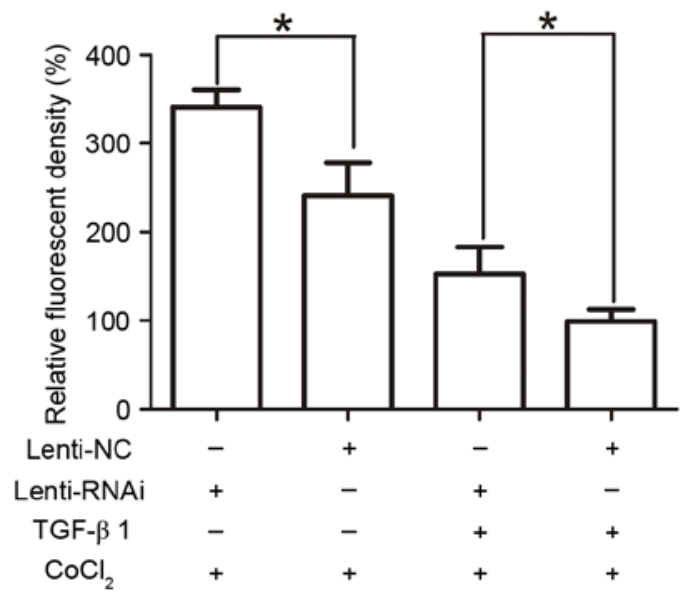

Figure 4.ZFP580 serves an important role in the protective effects of TGF- $\beta 1$ against $\mathrm{CoCl}_{2}$-induced apoptosis and $\mathrm{ROS}$ generation. $\mathrm{H} 9 \mathrm{c} 2 \mathrm{cells}$ were transfected with Lenti-RNAi or Lenti-NC lentiviral vectors for $72 \mathrm{~h}$, followed by treatment with or without TGF- $\beta 1$ and subsequent exposure to $600 \mu \mathrm{M} \mathrm{CoCl}{ }_{2}$ for $24 \mathrm{~h}$. (A and B) Cells $\left(1 \times 10^{4}\right)$ were subjected to AnnexinV-FITC/PI staining and analyzed by flow cytometry. (C) DCFH-DA (10 mM) fluorescence probe images were captured using a confocal microscope (Magnification, x200; bars, $25 \mu \mathrm{m}$ ). (D) Intracellular ROS generation was measured by a microplate reader in each of the indicated treatment groups. $\mathrm{A} 1$ and $\mathrm{C} 1$, Lenti-RNAi with $\mathrm{CoCl}_{2}$ exposure; $\mathrm{A} 2$ and $\mathrm{C} 2$, Lenti-NC with $\mathrm{CoCl}_{2}$ exposure; $\mathrm{A} 3$ and $\mathrm{C} 3, \mathrm{Lenti}-\mathrm{RNA}$ with TGF- $\beta 1$ pretreatment followed by $\mathrm{CoCl}_{2}$ exposure; $\mathrm{A} 4$ and $\mathrm{C} 4$, Lenti-NC with TGF- $\beta 1$ pretreatment followed by $\mathrm{CoCl}_{2}$ exposure. Three experiments were performed for each group, and each experiment was repeated twice. The results are presented as the mean \pm standard error. "P<0.05. ZFP580, zinc finger protein 580; TGF- $\beta 1$, transforming growth factor- $\beta 1 ; \mathrm{CoCl}_{2}$, cobalt chloride; ROS, reactive oxygen species; Lenti-RNAi, small interfering RNA lentiviral vectors directed against ZFP580; Lenti-NC, negative control lentiviral vectors; FITC, fluorescein isothiocyanate; PI, propidium iodide; DCFH-DA, 2,7-dichlorofluorescin diacetate.

ZFP580 serves an important role in the protective effects of TGF- $\beta 1$ against $\mathrm{CoCl}_{2}$-induced apoptosis and ROS generation. To evaluate the potential role of ZFP580 in the TGF- $\beta 1 /$ Smad2/3-mediated protection against $\mathrm{CoCl}_{2}$-induced apoptosis, it was hypothesized that TGF- $\beta 1$ pretreatment of $\mathrm{CoCl}_{2}$-induced hypoxic cells may stimulate the expression of ZFP580. H9c2 cells were transfected with lentiviral vectors expressing siRNAs directed against ZFP580 (Lenti-RNAi) or a negative control (Lenti-NC) and were subsequently pretreated with or without TGF- $\beta 1$, prior to exposure to $\mathrm{CoCl}_{2}$. Flow cytometric analysis indicated that suppression of ZFP580 significantly increased the proportion of apoptotic cells compared with the number of apoptotic cells in the Lenti-NC group $(35.90 \pm 2.92$ vs. $46.13 \pm 1.68 \%$; $\mathrm{P}<0.05)$.
Furthermore, the anti-apoptotic role of TGF- $\beta 1$ was reduced by Lenti-RNAi transfection (Fig. 4A and B). Analysis of ROS generation revealed that $\mathrm{CoCl}_{2}$ significantly induced ROS production in Lenti-RNAi cells compared with in Lenti-NC cells $(\mathrm{P}<0.05$; Fig. 4C-1, C- 2 , and $\mathrm{D})$. TGF- $\beta 1$ significantly decreased $\mathrm{CoCl}_{2}$-induced ROS generation, an effect that was reduced by Lenti-RNAi transfection (Fig. 4C-3, C-4, and D). These results indicated that ZFP580 serves an important role in the TGF- $\beta 1$-mediated cytoprotective effects against $\mathrm{CoCl}_{2}$-induced apoptosis and ROS generation.

ZFP580 is involved in the anti-apoptotic effects of TGF- $\beta 1$ through inhibition of the mitochondrial apoptotic pathway. The role of ZFP580 in the TGF- $\beta 1 / \mathrm{Smad} 2 / 3$ signaling 
A

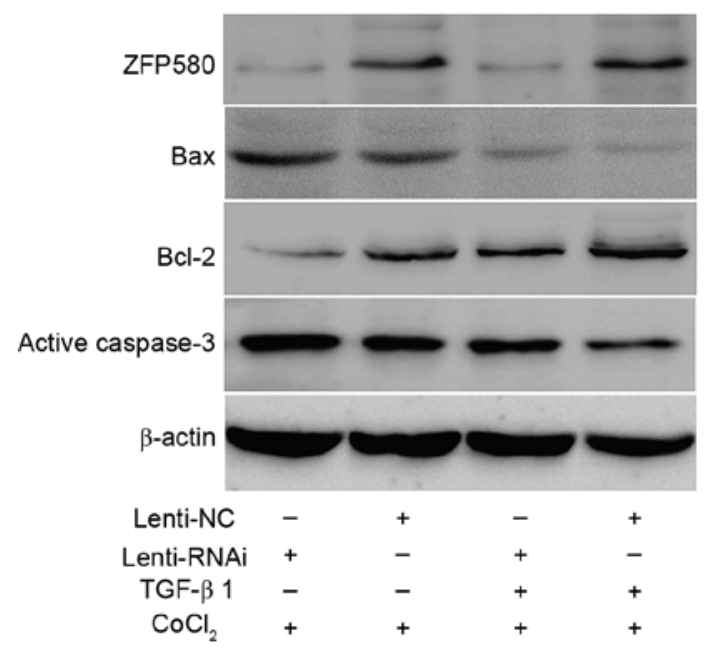

C

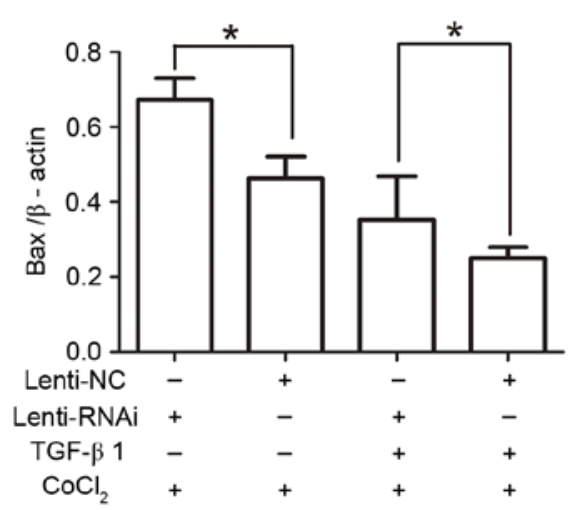

E

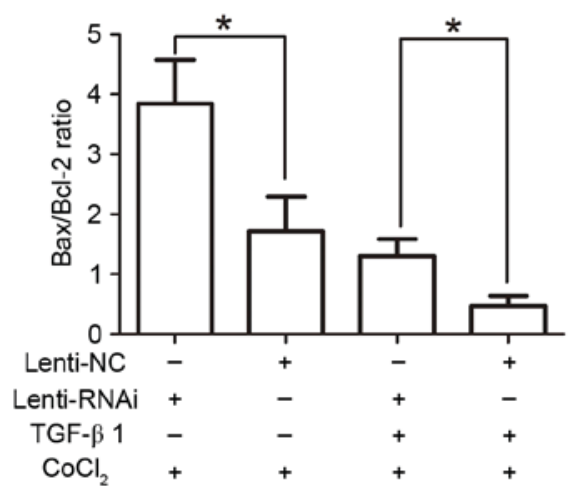

B

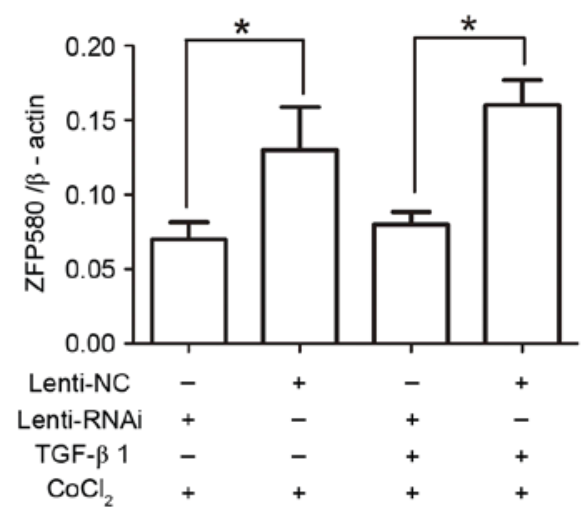

D

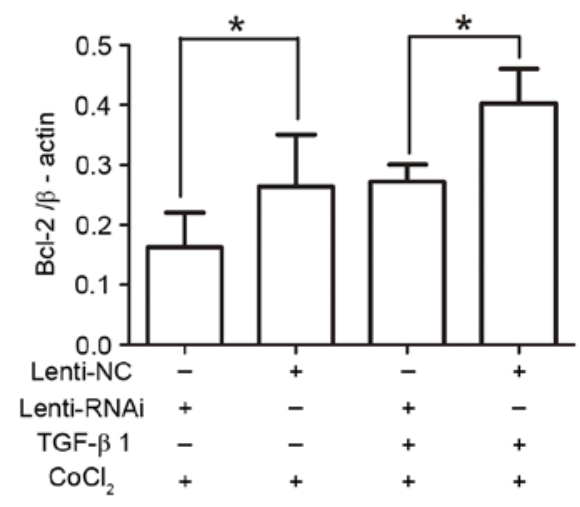

F

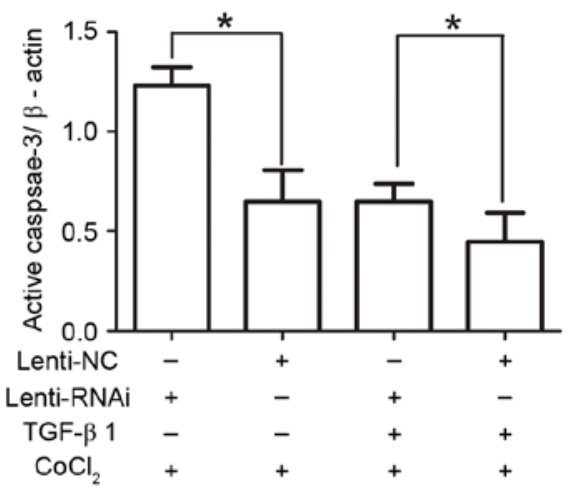

Figure 5. ZFP580 is involved in the anti-apoptotic effects of TGF- $\beta 1$ through inhibition of the mitochondrial apoptosis pathway. H9c2 cells were transfected with Lenti-RNAi or Lenti-NC lentiviral vectors for $72 \mathrm{~h}$, followed by treatment with or without TGF- $\beta 1$ and subsequent exposure to $600 \mu \mathrm{M} \mathrm{CoCl} l_{2}$ for $24 \mathrm{~h}$. (A) Western blot analysis, and histogram analysis of (B) ZFP580, (C) Bax, (D) Bcl-2, (E) Bax/Bcl-2 ratio, and (F) active caspase-3 in each of the indicated treatment groups. Three experiments were performed for each group, and each experiment was replicated twice. The results are presented as the mean \pm standard error "P<0.05. ZFP580, zinc finger protein 580; TGF- $\beta 1$, transforming growth factor- $\beta 1$; Lenti-RNAi, small interfering RNA lentiviral vectors directed against ZFP580; Lenti-NC, negative control lentiviral vectors; $\mathrm{CoCl}_{2}$, cobalt chloride; ROS, reactive oxygen species; $\mathrm{Bcl}-2$, B-cell lymphoma 2; Bax, Bcl-2-associated X protein .

pathway during $\mathrm{CoCl}_{2}$-induced apoptosis was investigated. Western blotting indicated that TGF- $\beta 1$ significantly increased the expression of the anti-apoptotic protein Bcl-2, and decreased the expression of the proapoptotic protein Bax, in Lenti-NC groups compared with Lenti-RNAi groups (Fig. 5). Furthermore, the Bax/Bcl-2 ratio and levels of active caspase-3 were decreased $(\mathrm{P}<0.05)$. However, suppression of ZFP580 reduced the anti-apoptotic effects of TGF- $\beta 1$, increased the $\mathrm{Bax} / \mathrm{Bcl}-2$ ratio, and promoted caspase-3 activation $(\mathrm{P}<0.05)$. These results demonstrated that ZFP580 is involved in the protective effects of TGF- $\beta 1$ against $\mathrm{CoCl}_{2}$-induced $\mathrm{H} 9 \mathrm{c} 2$ cell apoptosis, and may serve an important anti-apoptotic role through inhibition of the mitochondrial apoptotic pathways. 


\section{Discussion}

ZFP580 is a novel zinc finger protein with three C-terminal $\mathrm{C} 2 \mathrm{H} 2$ zinc finger domains and an $\mathrm{N}$-terminal proline-rich domain. The zinc finger is the most abundant protein motif in mammalian cells, and it is involved in the expression and regulation of numerous eukaryotic genes. $\mathrm{C} 2 \mathrm{H} 2 \mathrm{zinc}$ finger proteins in particular often have a crucial role in physiological cellular functions, such as growth and differentiation (3). Previous research has indicated that ZFP580 may be upregulated by hypoxic preconditioning, and may serve a critical anti-apoptotic role in myocardial ischemia and reperfusion injury (7). However, little is known regarding the regulation of ZFP580 expression and function under hypoxic conditions. In the present study, a $\mathrm{CoCl}_{2}$-induced hypoxia model was established in $\mathrm{H} 9 \mathrm{c} 2$ myocardial cells. The results demonstrated that $\mathrm{CoCl}_{2}$ treatment decreased cell viability and increased the expression of HIF-1 $\alpha$ protein, but not HIF- $1 \alpha$ mRNA. These findings are consistent with those of previous studies $(21,22)$. Conversely, ZFP580 mRNA and protein expression were upregulated by $\mathrm{CoCl}_{2}$ treatment. The observed ZFP580 mRNA expression trend was similar to that of the HIF-1 $\alpha$ protein, which is a protein marker of hypoxia. Therefore, it was hypothesized that ZFP580 may serve a role in hypoxia, and its expression may be regulated under hypoxic conditions.

Hypoxia regulates the expression of numerous genes and the secretion of multiple cytokines. Various growth factors, including hepatocyte growth factor, basic fibroblast growth factor and TGF- $\beta 1$, have important roles in tissues exposed to hypoxia or ischemia (9). The present study focused on TGF- $\beta 1$ due to previous research indicating that this growth factor exerts cardioprotective effects and mediates important anti-apoptotic effects in vitro and in vivo $(9,10,23)$. Our previous study demonstrated that the human gene ZNF580 was involved in the TGF- $\beta 1$ signaling pathway and interacted with the TGF- $\beta$ signal molecule Smad2 $(16,17)$. Therefore, it was hypothesized that ZFP580 may be involved in the cardioprotective effects of TGF- $\beta 1$. In the present study, MTT assay revealed that TGF- $\beta 1$ reduced chemical hypoxia-induced cytotoxicity and increased cell viability. Furthermore, it was discovered that TGF- $\beta 1$ upregulates ZFP580 expression in H9c2 cells with or without chemical hypoxia, however expression was highest under hypoxic conditions. These findings support the hypothesis that ZFP580 may be a downstream target of the TGF- $\beta 1$ signaling pathway and may mediate the protective effects of TGF- $\beta 1$.

Following TGF- $\beta 1$ binding to its cognate receptors, downstream intracellular signaling involves activation of the canonical pathway involving Smad 2/3, or the non-canonical signaling pathways, including extracellular signal-related kinase (ERK)1/2 and phosphoinositide-3-kinase-Akt $(11,24)$. Previous research has reported that activation of the TGF- $\beta 1$-dependent $S \operatorname{mad} 2 / 3$ pathway is correlated with the cardioprotective effects of TGF- $\beta 1$ against ischemia/reperfusion-induced apoptosis (25). The present study indicated that TGF- $\beta 1$ could significantly decrease $\mathrm{CoCl}_{2}$-induced apoptosis, however these effects were reduced following pretreatment with SB431542, an inhibitor of T $\beta$ R-I and Smad2/3 phosphorylation. These findings indicated that
TGF- $\beta 1$ was able to limit chemical hypoxia-induced H9c2 cell injury via activation of $S \operatorname{mad} 2 / 3$. Furthermore, it was demonstrated that inhibition of TGF $\beta$ R-I-Smad2/3 activation partially blocked the TGF- $\beta 1$-induced upregulation of ZFP580 expression. These results supported the hypothesis that ZFP580 is involved in the protective effect of TGF- $\beta 1$ against $\mathrm{CoCl}_{2}$-induced apoptosis, as a downstream target of the TGF- $\beta 1 / \mathrm{Smad} 2 / 3$ signaling pathway. ZFP580 has a similar structure to that of the Sp1-like/krüppel-like factor (KLF) transcription factor superfamily. Li et al reported that TGF- $\beta 1$ could increase the phosphorylation of KLF4 via Smad signaling pathways in vascular smooth muscle cells (26). Hence, it was further hypothesized that ZFP580 may be regulated by TGF- $\beta 1$ through canonical Smad signaling pathways. Our previous study demonstrated that ZFP580 has an anti-apoptotic function as a downstream target of the ERK pathway in myocardial ischemia and reperfusion injury (7). However, whether other non-canonical signaling pathways have critical roles in the regulation of ZFP580 by TGF- $\beta 1$ is worth exploring further.

Hypoxia/ischemia may induce a series of pathological changes, including apoptosis and necrosis. Three major pathways can regulate apoptosis: Extracellular Fas protein; mitochondria; and endoplasmic reticulum. $\mathrm{CoCl}_{2}$ was previously reported to promote hypoxic/ischemic responses by increasing ROS generation, dissipating the mitochondrial membrane potential, activating caspase- 3 , decreasing cell viability and inducing apoptosis $(20,27,28)$. A study in rat pheochromocytoma $\mathrm{PC} 12$ cells indicated that $\mathrm{CoCl}_{2}$-induced apoptosis may be associated with the mitochondrial-mediated apoptosis pathway (29). This mitochondrial pathway is predominantly mediated by members of the Bcl-2 family, and is triggered as a result of cell injury induced by DNA damage or cell distress. This leads to mitochondrial disruption and the release of apoptotic mediators, such as apoptosis inducing factor and cytochrome $c$ into the cytoplasm, thereby inducing activation of the caspase cascade (30). Furthermore, numerous reports have demonstrated that Bax, Bcl-2 and caspase- 3 act as downstream molecules of TGF- $\beta 1$ signaling in some cases of apoptosis $(8,31,32)$. Therefore, the present study investigated the protective mechanisms mediated by ZFP580 and TGF- $\beta 1$ against $\mathrm{CoCl}_{2}$-induced apoptosis in the mitochondrial-mediated apoptotic pathway. The results demonstrated that TGF- $\beta 1$ upregulated the anti-apoptotic protein $\mathrm{Bcl}-2$, downregulated the proapoptotic protein Bax, suppressed ROS generation and reduced the activation of caspase-3, which is a final executioner protein in the apoptotic cascade. Conversely, suppression of ZFP580 expression by RNA interference enhanced $\mathrm{CoCl}_{2}$-induced cell apoptosis and reduced the anti-apoptotic role of TGF- $\beta 1$. These findings suggested that ZFP580 may be a component of the anti-apoptotic process mediated by the TGF- $\beta 1 / \mathrm{Smad}$ signaling pathway.

In conclusion, the present study provided experimental evidence that ZFP580 may function as a novel cytoprotective regulator under hypoxic conditions. It was demonstrated that ZFP580 serves an essential role in mediating the cardioprotective effect of TGF- $\beta 1$ against chemical hypoxia-induced cell apoptosis by inhibiting the mitochondrial apoptotic pathway. 


\section{Acknowledgements}

The authors would like to thank colleagues in the Department of Physiology and Pathophysiology, Logistics University of Chinese People's Armed Police Force for their excellent technical assistance and encouragement. They would also like to thank Dr Xin Zhou and Dr WenJie Ji (Tianjin Key Laboratory of Cardiovascular Remodeling and Target Organ Injury, Pingjin Hospital Heart Center, Tianjin, China) for their help in the flow cytometry study. This study was supported by funds from the National Natural Science Foundation of China (grant no. 81173588); the Tianjin Natural Science Foundation (grant no. 12JCYBJC15900); and the Tianjin Key Laboratory for the Prevention and Control of Occupational and Environmental Hazard (grant no. TJC1409).

\section{References}

1. Zhang WC, Chen BS, Zeng WW and Wu G: Cloning and tissue expression of a novel gene down-regulated by low density lipoprotein. Basic Med Sci Clin 23: 279-282, 2003.

2. Zhang WC, Sun HY and Luo YY: Construction of eukaryotic expression vector for ZNF580 and EGFP fusion protein and its expression and localization in HEK293 cells. Acta Acad Med CPAF 17: 161-165, 2008.

3. Thomas JH and Emerson RO: Evolution of $\mathrm{C} 2 \mathrm{H} 2$-zinc finger genes revisited. BMC Evol Biol 9: 51, 2009.

4. DangLi R, HeKong W, JiQin L, MingHua Z and WenCheng Z: ROS-induced ZNF580 expression: A key role for $\mathrm{H}_{2} \mathrm{O}_{2} / \mathrm{NF}-\kappa \mathrm{B}$ signaling pathway in vascular endothelial inflammation. Mol Cell Biochem 359: 183-191, 2012.

5. Sun HY, Wei SP, Xu RC, Xu PX and Zhang WC: Sphingosine-1-phosphate induces human endothelial VEGF and MMP-2 production via transcription factor ZNF580: Novel insights into angiogenesis. Biochem Biophys Res Commun 395: 361-366, 2010.

6. Zhu Y and Zhang W: Cloning and analyzing of the cDNA sequence of $\mathrm{N}$-terminal region and $\mathrm{C}$-terminal region of zinc finger protein (ZFP580) gene. Life Science Journal 5: 68-73, 2008.

7. Meng XY, Yu HL, Zhang WC, Wang TH, Mai X, Liu HT and Xu RC: ZFP580, a novel zinc-finger transcription factor, is involved in cardioprotection of intermittent high-altitude hypoxia against myocardial ischemia-reperfusion injury. PLoS One 9: e94635, 2014.

8. Chen H, Li D, Saldeen T and Mehta JL: TGF-beta 1 attenuates myocardial ischemia-reperfusion injury via inhibition of upregulation of MMP-1. Am J Physiol Heart Circ Physiol 284: H1612-H1617, 2003.

9. Dandapat A, Hu CP, Li D, Liu Y, Chen H, Hermonat PL and Mehta JL: Overexpression of TGFbetal by adeno-associated virus type- 2 vector protects myocardium from ischemia-reperfusion injury. Gene Ther 15: 415-423, 2008

10. Frantz S, Hu K, Adamek A, Wolf J, Sallam A, Maier SK, Lonning S, Ling H, Ertl G and Bauersachs J: Transforming growth factor beta inhibition increases mortality and left ventricular dilatation after myocardial infarction. Basic Res Cardiol 103: 485-492, 2008.

11. Al-Azayzih A, Gao F, Goc A and Somanath PR: TGF $\beta 1$ induces apoptosis in invasive prostate cancer and bladder cancer cells via Akt-independent, p38 MAPK and JNK/SAPK-mediated activation of caspases. Biochem Biophys Res Commun 427: 165-170, 2012.

12. Fu MY, He YJ, Lv X, Liu ZH, Shen Y, Ye GR, Deng YM and Shu JC: Transforming growth factor- $\beta 1$ reduces apoptosis via autophagy activation in hepatic stellate cells. Mol Med Rep 10: 1282-1288, 2014.

13. Sánchez-Capelo A: Dual role for TGF-beta1 in apoptosis. Cytokine Growth Factor Rev 16: 15-34, 2005.

14. Baxter GF, Mocanu MM, Brar BK, Latchman DS and Yellon DM: Cardioprotective effects of transforming growth factor-beta1 during early reoxygenation or reperfusion are mediated by p42/p44 MAPK. J Cardiovasc Pharmacol 38: 930-939, 2001.
15. Yang BC, Zander DS and Mehta JL: Hypoxia-reoxygenationinduced apoptosis in cultured adult rat myocytes and the protective effect of platelets and transforming growth factor-beta(1). J Pharmacol Exp Ther 291: 733-738, 1999.

16. Luo Y, Zhao Y, Li X, Zhao J and Zhang W: ZNF580 mediates eNOS expression and endothelial cell migration/proliferation via the TGF- $\beta 1 /$ ALK5/Smad2 pathway. Mol Cell Biochem 393: 199-207, 2014.

17. Luo Y, Hu W, Xu R, Hou B, Zhang L and Zhang W: ZNF580, a novel $\mathrm{C} 2 \mathrm{H} 2$ zinc-finger transcription factor, interacts with the TGF- $\beta$ signal molecule Smad2. Cell Biol Int 35: 1153-1157, 2011.

18. Tong XX, Wu D, Wang X, Chen HL, Chen JX, Wang XX, Wang XL, Gan L, Guo ZY, Shi GX, et al: Ghrelin protects against cobalt chloride-induced hypoxic injury in cardiac H9c2 cells by inhibiting oxidative stress and inducing autophagy. Peptides 38: 217-227, 2012.

19. Livak KJ and Schmittgen TD: Analysis of relative gene expression data using real-time quantification PCR and the 2(-Delta Delta C(T)) method. Methods 25: 402-408, 2001.

20. Chen SL, Yang CT, Yang ZL, Guo RX, Meng JL, Cui Y, Lan AP, Chen PX and Feng JQ: Hydrogen sulphide protects H9c2 cells against chemical hypoxia-induced injury. Clin Exp Pharmacol Physiol 37: 316-321, 2010

21. Yuan Y, Hilliard G, Ferguson T and Millhorn DE: Cobalt inhibits the interaction between hypoxia-inducible factor-alpha and von Hippel-Lindau protein by direct binding to hypoxia-inducible factor-alpha. J Biol Chem 278: 15911-15916, 2003.

22. Wang K, Lei J, Zou J, Xiao H, Chen A, Liu X, Liu Y, Jiang L, $\mathrm{Xiao} \mathrm{Z}$ and Xiao X: Mipu1, a novel direct target gene, is involved in hypoxia inducible factor 1-mediated cytoprotection. PLoS One 8: e82827, 2013.

23. Mehta JL, Chen HJ and Li DY: Protection of myocytes from hypoxia-reoxygenation injury by nitric oxide is mediated by modulation of transforming growth factor-beta1. Circulation 105: 2206-2211, 2002.

24. Wang F, Chen L, Ni H, Wang G, Ding W, Cong H, Ju S, Yang S and Wang H: APRIL depletion induces cell cycle arrest and apoptosis through blocking TGF- $\beta 1 /$ ERK signaling pathway in human colorectal cancer cells. Mol Cell Biochem 383: 179-189, 2013.

25. Vivar R, Humeres C, Ayala P, Olmedo I, Catalán M, García L, Lavandero S and Díaz-Araya G: TGF- $\beta 1$ prevents simulated ischemia/reperfusion-induced cardiac fibroblast apoptosis by activation of both canonical and non-canonical signaling pathways. Biochim Biophys Acta 1832: 754-762, 2013.

26. Li HX, Han M, Bernier M, Zheng B, Sun SG, Su M, Zhang R, Fu JR and Wen JK: Kruppel-like factor 4 promotes differentiation by transforming growth factor-beta receptor-mediated Smad and p38 MAPK signaling in vascular smooth muscle cells. J Biol Chem 285: 17846-17856, 2010

27. Lan A, Liao X, Mo L, Yang C, Yang Z, Wang X, Hu F, Chen P, Feng J, Zheng D and Xiao L: Hydrogen sulfide protects against chemical hypoxia-induced injury by inhibiting ROS-activated ERK1/2 and p38MAPK signaling pathways in PC12 cells. PLoS One 6: e25921,2011.

28. Wang Z, Liao SG, He Y, Li J, Zhong RF, He X, Liu Y, Xiao TT, Lan YY, Long QD and Wang YL: Protective effects of fractions from Pseudostellaria heterophylla against cobalt chloride-induced hypoxic injury in H9c2 cell. J Ethnopharmacol 147: 540-545, 2013.

29. Jung JY, Mo HC, Yang KH, Jeong YJ, Yoo HG, Choi NK, Oh WM, Oh HK, Kim SH, Lee JH, et al: Inhibition by epigallocatechin gallate of $\mathrm{CoCl} 2$-induced apoptosis in rat $\mathrm{PC} 12$ cells. Life Sci 80: 1355-1363, 2007.

30. Tan CY, Ban H, Kim YH and Lee SK: The heat shock protein 27 (Hsp27) operates predominantly by blocking the mitochondrial-independent/extrinsic pathway of cellular apoptosis. Mol Cells 27: 533-538, 2009.

31. Bakhshayesh M,Zaker F, Hashemi M,Katebi M and Solaimani M: TGF- $\beta 1$-mediated apoptosis associated with SMAD-dependent mitochondrial $\mathrm{Bcl}-2$ expression. Clin Lymphoma Myeloma Leuk 12: 138-143, 2012 .

32. Surachetpong S, Jiranantasak T, Rungsipipat A and Orton EC: Apoptosis and abundance of Bcl-2 family and transforming growth factor $\beta 1$ signaling proteins in canine myxomatous mitral valves. J Vet Cardiol 15: 171-180, 2013. 